Original Article

\title{
Nitensidine B affects proteins of the glycolytic pathway and induces apoptosis in cervical carcinoma cells immortalized by HPV16
}

\author{
Felipe de Oliveira Souza ${ }^{\mathrm{a}}$, Juliana Maria Sorbo ${ }^{\mathrm{a}}$, Luís Octávio Regasini ${ }^{\mathrm{b}}$, \\ Vanderlan da Silva Bolzani ${ }^{\mathrm{c}}$, José César Rosa ${ }^{\mathrm{d}}$, Érica da Silva Czernys ${ }^{\mathrm{d}}$, Valéria Valente ${ }^{\mathrm{a}}$, \\ Thaís Fernanda Moreira ${ }^{\mathrm{a}}$, Geovana Navegante ${ }^{\mathrm{a}}$, Barbara Colatto Fernandes ${ }^{\mathrm{a}}$, \\ Christiane Pienna Soares ${ }^{\mathrm{a}, *}$
}

\footnotetext{
a Department of Clinical Analysis, School of Pharmaceutical Sciences, Sao Paulo State University, Highway Araraquara Jaú, Km 01, Campos Ville, Araraquara, Sao Paulo, Brazil

${ }^{\mathbf{b}}$ Department of Chemistry and Environmental Sciences of the Institute of Biosciences, Letters and Exact Sciences of the Sao Paulo State University, Cristovao Colombo street, 2265, Sao Jose do Rio Preto, Sao Paulo, Brazil

${ }^{\mathrm{c}}$ Department of Organic Chemistry, Institute of Chemistry, São Paulo State University, 355, 14800-900 Araraquara, Brazil

d Center of Protein Chemistry of Department of Cellular Molecular Biology and Pathogen Bioagents of the Faculty of Medicine of Ribeirao Preto, University of Sao Paulo,
} Avenue Bandeirantes, 3900, Ribeirao Preto, Sao Paulo, Brazil

\section{A R T I C L E I N F O}

\section{Keywords:}

Cervical cancer

Nitensidine B

Apoptosis

Proteomic analysis

Glycolytic pathway

\begin{abstract}
A B S T R A C T
Background: Cervical cancer, the fourth most common type of cancer among women worldwide, accounts for approximately $12 \%$ of all types of malignancies that affect women. Natural products have contributed significantly to the development of modern therapies; approximately $70 \%$ of the drugs available for chemotherapy are naturally based products.

Purpose: The purpose of this study was to examine the biological activities of nitensidine B (NTB), a guanidinic alkaloid isolated from the leaves of Pterogyne nitens Tul. (Fabaceae) in a cervical cancer cell line.

Methods: In vitro experiments were performed using cervical carcinoma cells immortalized by human papillomavirus type 16 (HPV16, SiHa cells), since epidemiological and molecular studies have demonstrated robust associations between the etiologies of cervical cancer and HPV infection. Cytotoxicity as well as the effect of NTB treatment on intracellular signals of apoptosis, fragmentation of internucleosomal DNA via terminal deoxynucleotidyl transferase dUTP nick end labeling (TUNEL), and levels of apoptosis effectors (Caspase 3/7) were evaluated. In addition, differential proteomic analysis (iTRAQ) and protein validation using western blot were performed.

Results: The cytotoxicity of NTB treatment in the SiHa cell line was concentration-dependent, with the minimum inhibitory concentration of $50 \%$ of the cells of $40.98 \mu \mathrm{M}$. In the TUNEL assay, SiHa cell apoptosis with $3 / 7$ caspase activation was reported at $12 \mathrm{~h}$ following treatment. Differential proteomic analysis by iTRAQ demonstrated that proteins of the glycolytic pathway, aldolase A, alpha-enolase, pyruvate kinase, and glyceraldehyde 3-phosphate dehydrogenase were underexpressed.

Conclusion: These results indicated that NTB could play a role in decreasing glycolysis . Since tumor cells prefer the glycolytic pathway to generate energy, these findings suggest that NTB may be a reliable model for the study of human cervical cancer cell lines immortalized by HPV16, however more experiments can be performed.
\end{abstract}

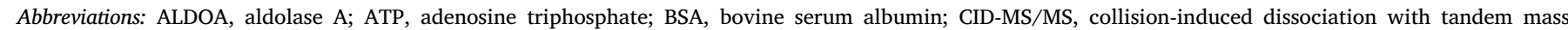

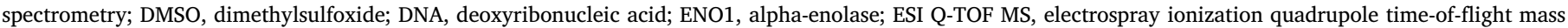

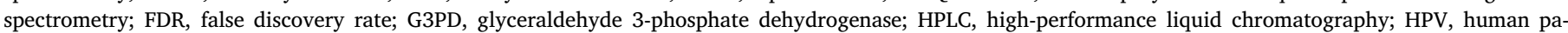

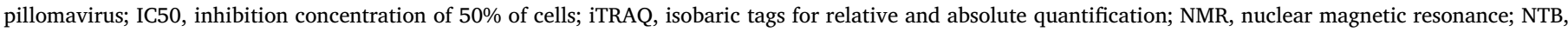

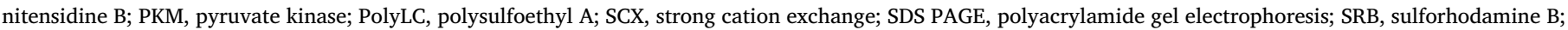

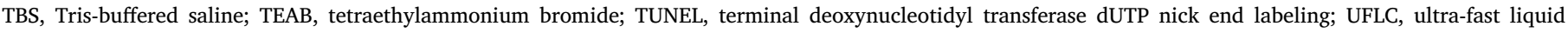
chromatography

* Corresponding author.

E-mail address: soarescp@fcfar.unesp.br (C.P. Soares). 


\section{Introduction}

Cervical cancer is the fourth most prevalent cancer in women worldwide, accounting for 528,000 of the new cases of cancer diagnosed each year. Approximately 266,000 women die annually from invasive cervical cancer, $80 \%$ of which are reported in developing countries (Ferlay et al., 2014). In approximately $90 \%$ of cases, cervical cancer is associated with human papillomavirus (HPV). More than 200 genomes of HPV have been identified and about 40 of them are associated with lesions of the genital tract, mainly classified as low and high oncogenic risk. Low risk types are associated with HPV 6, 11, 42, 43, and 44 while the high risk serological types associated with pre-cancerous lesions are HPV 16, 18, 31, 33, 35, 45, 51, 52, 53, 56, 58, 59, 63, 66, 68, 82, and 56 (Gebremariam, 2016; Rosa et al., 2009).

Although most antineoplastic therapies provide benefits for patients, they are also associated with adverse effects. As such, natural products can contribute significantly to the development of new drugs (Shanmugam et al., 2016). As part of our studies on Brazilian natural products, we aimed to characterize the activity of nitensidine B (NTB) (Fig. 1), a guanidine alkaloid isolated from plants of the Fabaceae family, against a human cervical cell line immortalized with HPV16 (SiHa). The biological activities of alkaloids derived from Pterogyne nitens reported in the literature include: antiparasitic, antifungal, cytotoxic against breast cancer, melanoma, human leukemia, colon carcinoma, and human glioblastoma (Duarte et al., 2010; Regasini et al., 2009; Regasini et al., 2010).

In this study, we assessed the cytotoxicity of NTB using tests for detection and quantification of apoptosis in the SiHa cell line. Differential proteomic analysis was conducted in order to investigate the mechanisms of action of NTB in SiHa cells and identify possible therapeutic targets (Chavan et al., 2006; Ulrich-Merzenich et al., 2007; Verpoorte et al., 2005). The data obtained from the differential proteomic analysis showed that NTB interferes in the glycolytic pathway of SiHa cells, indicated by a decrease in the production of proteins involved in this process, as well as promotes induction of cellular apoptosis.

\section{Materials and methods}

Plant material

Pterogyne nitens leaves were collected at the Botanic Institute, São Paulo, Brazil between April and May 2003 and then deposited at the Herbarium of Maria Eneida P. Kaufmann of the Botanic Institute, São Paulo under a voucher specimen (SP204319).

\section{Extraction and purification of nitensidine $B$}

Nitensidine B is an isolated compound and their chemical characterization was detailed and described in Regasini et al. (2010) and Tajima et al. (2014).

\section{Cell culture}

SiHa cells, a cervical carcinoma line containing an integrated HPV16 genome (American Type Culture Collection [ATCC] HTB-35, Manassas, VA, USA), were grown in Dulbecco's modified eagle medium (DMEM) and Ham's F-10 (Sigma-Aldrich, St. Louis, USA). The Ham's F10 nutrient mixture was supplemented with $100 \mathrm{U} / \mathrm{ml}$ penicillin, $100 \mu \mathrm{g} / \mathrm{ml}$ streptomycin, $0.25 \mu \mathrm{g} / \mathrm{ml}$ amphotericin B, $0.1 \mathrm{mg} / \mathrm{ml}$ kanamycin (Sigma-Aldrich), and $10 \%$ fetal bovine serum (Cultilab, Campinas, Brazil) at $37{ }^{\circ} \mathrm{C}$ in a humidified incubator containing $5 \%$ $\mathrm{CO}_{2}$.

\section{Cytotoxicity and cell viability assay}

NTB cytotoxicity screening was performed in the SiHa cell line using the standard sulforhodamine B (SRB) method, previously described by Skehan and Storeng (1990). Exponentially growing cells were seeded in 96-well cell culture plates (TPP) at $1.5 \times 10^{4}$ cells $/ \mathrm{ml}$. After $24 \mathrm{~h}$, cells were treated with various concentrations of the isolated alkaloid (from $7.5 \mu \mathrm{M}$ to $120.0 \mu \mathrm{M})$. Doxorubicin, a chemotherapeutic drug used in the treatment of cervical cancer was used as positive control and

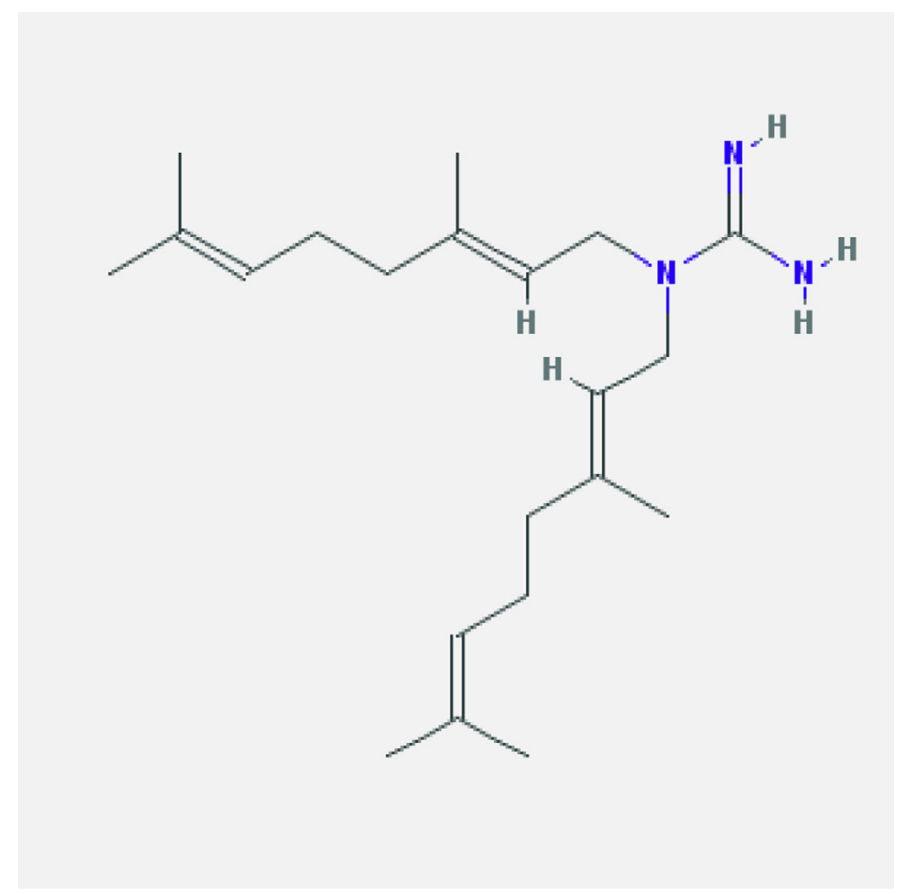

Fig. 1. Molecular structure of nitensidine B (molecular weight: 331.548 g/mol). PubChem CID: 10404473. 
dimethylsulfoxide (DMSO) as a vehicle control (Lee et al., 2014). After $72 \mathrm{~h}$ of incubation, cells were fixed with $50 \%(\mathrm{w} / \mathrm{v})$ trichloroacetic acid (Sigma-Aldrich) for $60 \mathrm{~min}$ at $4{ }^{\circ} \mathrm{C}$ and then stained with $0.4 \%$ SRB (diluted in 1\% acetic acid) for $30 \mathrm{~min}$. Wells were washed with distilled water and dried at room temperature. Plates were incubated in contact with the dye $(0.4 \% \mathrm{SRB}$, diluted in $1 \%$ acetic acid) for $30 \mathrm{~min}$. Then, the dye was solubilized using Tris with hydrochloric acid for $5 \mathrm{~min}$. The optical density was measured using an absorbance of $570 \mathrm{~nm}$ in a spectrophotometric microplate reader (iMark, Bio-Rad, Hercules, CA, USA) (Skehan and Storeng, 1990; Voigt, 2005).

In situ assessment of apoptosis by TUNEL assay

Apoptosis assays were performed using terminal deoxynucleotidyl transferase dUTP nick end labeling (TUNEL) reaction mixtures (In Situ Cell Death Detection Kit, Fluorescein, Roche, Mannheim, Germany), according to the manufacture's protocol. SiHa cells were seeded in 96well microplates and treated with different concentrations of NTB (from 30.0 to $120.0 \mu \mathrm{M})$. Curcumin was chosen as positive control for being also a natural product well established as a potent inducer of apoptosis and DMSO was used as the vehicle control (Zaman et al., 2016). Fixed cells were incubated with the TUNEL reaction mixture and image acquisition and processing were performed using an IN Cell Analyzer 2000 (GE Healthcare Life Sciences, Piscataway, NJ, USA).

\section{Caspase 3/7 activation assay}

Caspase 3/7 activity was determined using a caspase-3 colorimetric assay kit (Caspase-Glo ${ }^{\circledR} 3 / 7$, Promega, Madison, WI, USA) according to the manufacturer's protocol. SiHa cells were treated with NTB for 6,12 , and $24 \mathrm{~h}$. Curcumin was used as the positive control and DMSO was used as the vehicle control. Caspase-Glo ${ }^{\oplus} 3 / 7$ Reagent (25 $\left.\mu 1,1: 1\right)$ was added to each sample and the plate was incubated for $1 \mathrm{~h}$ at room temperature. The luminescent reading of each sample was performed in a plate luminometer (Corning ${ }^{\circledR} 96$ Well Solid White Flat Bottom Polystyrene TC-Treated Microplates, One Riverfront Plaza, NY, USA).

\section{Protein extraction and iTRAQ labeling}

For differential proteomic analysis, the aim of our study was to compare the treated SiHa cells with the untreated SiHa cells and establish the possible mechanisms of action. SiHa cells were collected $24 \mathrm{~h}$ after NTB treatment (Concentration of $30.0 \mu \mathrm{M}$ of NTB was used based on studies of Lai et al. (2014,2015)) and untreated cells were mixed with $7.7 \mathrm{M}$ urea, $2.2 \mathrm{M}$ thiourea, $4.4 \%$ CHAPS detergent, and protease inhibitors. The protein extract $(1 \mathrm{mg})$ was reduced and alkylated according to the manufacturer's protocol (Applied Biosystem, Foster City, CA). The reduced and alkylated sample was diluted four times with $1 \mathrm{M}$ tetraethylammonium bicarbonate (TEAB) to a final concentration of $100 \mathrm{mM}$ at $\mathrm{pH}$ 8.0. Suitable amounts of $1 / 50$ of trypsin (Sequencing Grade Modified Trypsin, Promega) diluted in 0.1 M TEAB were added and the hydrolysis reaction was maintained for $24 \mathrm{~h}$ at $37{ }^{\circ} \mathrm{C}$. Protein extracts digested with trypsin were then labeled with different isobaric reagents 8 plex (isobaric tag for relative and absolute quantitation [iTRAQ], Applied Biosystems, Foster City, CA, USA). Each sample treated and non treated with NTB were digested by trypsin and they were isobaric labeled by the followed iTRAQ tag (113-114, control; 115-116, samples treated with NTB, Duplicate of biological replicates were analyzed using Scaffold V. 4.1.1 (Proteome Software, Portland, OR).

Chromatography in column of ionic exchange (SCX) and mass spectrometry

After iTRAQ-labeled samples were pooled, the samples were centrifuged and applied on a Polysulfoethyl A (PolyLC INC, Columbia, MD, USA) cathion exchange column of a high pressure liquid chromatography (HPLC) system, developed in a linear gradient of solvent $\mathrm{A}\left(10 \mathrm{mM} \mathrm{KH} \mathrm{PO}_{4} / 20 \%\right.$ acetonitrile [ACN, HPLC grade], $\mathrm{pH}$ 2.7) and solvent $\mathrm{B}\left(10 \mathrm{mM} \mathrm{KH} \mathrm{PO}_{4}, 0.5 \mathrm{M} \mathrm{NaCl} / 20 \% \mathrm{ACN}, \mathrm{pH} 2.7-3.0\right)$. The flow rate was $1 \mathrm{ml} / \mathrm{min}$ and $1 \mathrm{ml}$ fractions were collected. The strong cation exchange (SCX) fractions were desalted and separated using HPLC with a micro-column $(50 \mathrm{~mm} \times 4.0 \mathrm{~mm})$ packed with Vydac C18 reverse phase resin and analyzed online by electrospray ionization quadrupole time-of-flight mass spectrometry (ESI Q-TOF MS, Q-TOFUltima, Waters, Manchester, UK).

The samples were applied on a nano ultra-fast liquid chromatography (nano-UFLC, Shimadzu, Kyoto, Japan) with a reverse phase C18 column, coupled online to an ESI Q-TOF mass spectrometer. The spectra obtained from tandem mass spectrometry (CID-MS/MS) were collected, processed, and analyzed using MassLynx 4.0 (Milford, Massachusetts, USA).

\section{Identification of proteins}

The spectra were processed and submitted to a database to identify the proteins. We used Mascot version 2.2.04 (Matrix Science, London, UK), SwissProt database, and Homo sapiens taxonomy, with the following parameters: enzyme trypsin with loss of one cleavage, fixed modification for Methionyl-Cys, and variable modifications for methionine oxidation. In order to exclude false discovery rates (FDR), the mass spectra were submitted to the database in the reverse mode, using a level of statistical significance of $\mathrm{p}<0.05$. This indicated an allowed error of $5 \%$, which was a score for peptides $>35$, corresponding to ions of the consecutive $\mathrm{y}$ or $\mathrm{b}$ series for the sequencing of peptide amino acids, using collision-induced dissociation with MS/MS (CID-MS/MS).

\section{Quantification of protein expression levels}

For quantification of the differentially expressed proteins, the Scaffold Software for MS/MS Proteomics (Scaffold4, Proteome Software, Inc., Portland, OR, USA) was used. The cut-off was determined using the values for subexpression and overexpression (fold change), which indicated how much the expression of proteins were altered relative to their basal conditions. For this study, the cut-off was greater than or equal to 1.3 for the overexpression criterion and less than or equal to 0.7 for values of subexpressed proteins.

\section{Western blotting}

Proteins from SiHa cell lysates were subjected to polyacrylamide gel electrophoresis (SDS PAGE) using 10\% polyacrylamide. Bands were transferred to a nitrocellulose membrane (GE Healthcare Life Sciences) using a semi-dry system (Bio-Rad). The membranes were blocked with $0.05 \%$ Tris-buffered saline (TBS), $1 \%$ of bovine serum albumin (BSA), and Tween 20 solution for $60 \mathrm{~min}$ at room temperature and then incubated with primary antibodies, including anti-ALDOA rabbit (1:250) and anti-ENO1 (1:1000). All primary antibodies were purchased from Cusabio Biotech Co. (Wuhan, China). Membranes were washed and blots were incubated with rabbit anti-IgG conjugated to horseradish peroxidase (Abcam Biotech, Cambridge, MA, USA) for $60 \mathrm{~min}$ at room temperature. Blots were scanned and band intensities were quantified using LI-COR Image Studio Digits 4.0 software (LI-COR, Lincoln, NE, USA).

\section{Statistical analysis}

One-way analysis of variance (ANOVA) followed by the Tukey posthoc tests were conducted to compare groups for the cytotoxicity SRB, TUNEL, and caspases $3 / 7$ activation assays as well as the western blot results. GraphPad Prism 6.0 software was used in these analyses and $p<0.05$ was considered to be statistically significant. 


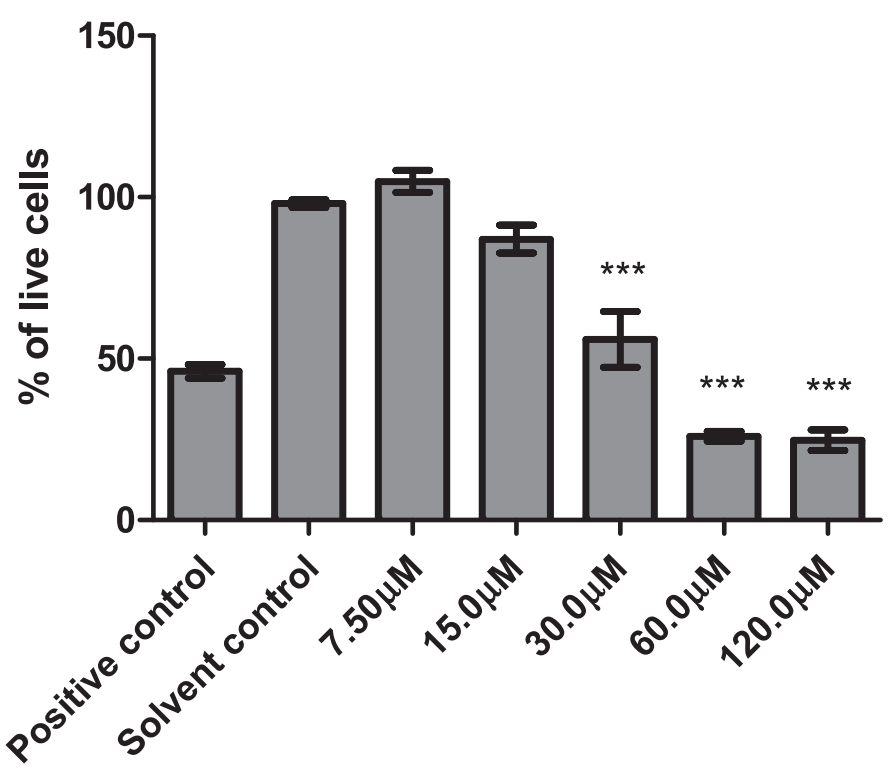

Results

Nitensidine $B$ reduces cell viability by apoptosis activation

The SRB results showed that cell viability decreased on treatment with NTB in a dose-dependent manner (Fig. 2). Following the addition of different concentrations of NTB $(7.5-120.0 \mu \mathrm{M})$, the cell viability of the $30.0,60.0$, and $120.0 \mu \mathrm{M}$ treatment groups significantly decreased compared to that of the control groups $(p<0.001)$. The IC ${ }_{50}$ for NTB treatment after $24 \mathrm{~h}$ was $40.98 \mu \mathrm{M}$.

The TUNEL assay (Figs. 3 and 4) showed activation of apoptosis following treatment with NTB. The number of TUNEL-positive cells in the treated group increased significantly compared to that of the control group. Treatment with 30.0, 60.0, and $120.0 \mu \mathrm{M}$ induced apoptosis and the percentage of TUNEL-positive cells was 15.4, 75.0 and 92.6, respectively.

Exposure of SiHa cells to NTB resulted in caspase- 3 and caspase-7 activation after 6,12 , and $24 \mathrm{~h}$, compared with DMSO-treated control cells (Fig. 5A-C). The activation of the caspase $3 / 7$ enzymes was significant at $12 \mathrm{~h}$ (Fig. 5B), with $p<0.05$ in the group treated with

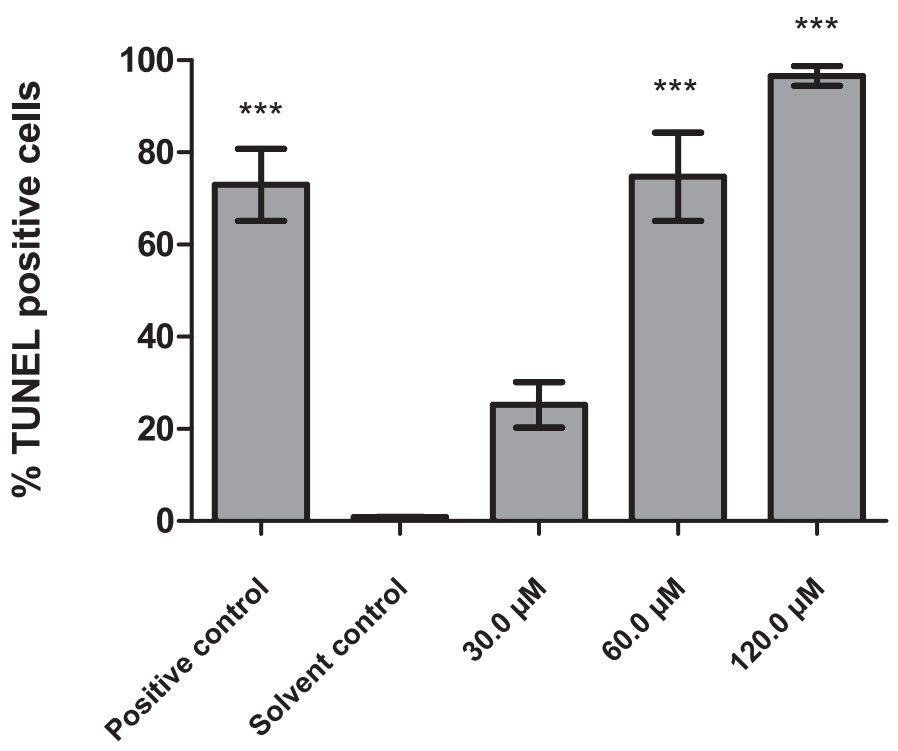

Fig. 2. Cytotoxicity assay (SRB). SiHa cell line treated with NTB at concentrations of $7.5,15.0,30.0,60.0$, and $120.0 \mu \mathrm{M}$ following $24 \mathrm{~h}$ of treatment. The data refer to the means of three independent experiments and standard deviation (M $\pm \mathrm{SD}$ ). Positive control: $90.0 \mu \mathrm{M}$ doxorubicin and Solvent control: $0.5 \%$ DMSO. One-way ANOVA with Tukey post-hoc tests (treated cells versus solvent control). ${ }^{*} p<0.05 * * p<0.01 * * * p<0.001$.
$30.0 \mu \mathrm{M}$ and $p<0.001$ in the groups treated with 60.0 and $120.0 \mu \mathrm{M}$ NTB.

Proteomic analysis revealed that nitensidine B downregulates glycolysis pathway of SiHa cells

Our results identified 125 proteins in response to treatment with NTB, 13 proteins differentially expressed (supplementary material) and 4 proteins were chosen (Table 1 ) because it seems be the main mechanism of action of NTB. An iTRAQ ratio or fold change $\leq 0.7$ was used to determine protein down-regulation while values $\geq 1.3$ were used to determine up-regulation. Table 1 shows four proteins related to the glycolytic pathway. Aldolase A fructose-bisphosphate (ALDOA, $0.05 \pm 0.01$ ), alpha-enolase (ENO1, $0.65 \pm 0.01$ ), and pyruvate kinase $(\mathrm{PKM}, 0.60 \pm 0.02)$ were shown to be down-regulated, while glyceraldehyde-3-phosphate dehydrogenase (G3PD) had an iTRAQ ratio of $0.72 \pm 0.10$

Western blots were performed to evaluate the expression of ALDOA and ENO1 proteins in SiHa cells. The SiHa cells were treated with 7.5, 15.0 , and $30.0 \mu \mathrm{M}$ of NTB for $24 \mathrm{~h}$. Our data showed that treatment

Fig. 3. Apoptosis by TUNEL assay in SiHa cell line treated with NTB at concentrations of $30.0,60.0$, and $120.0 \mu \mathrm{M}$. The data refer to the means of three independent experiments and standard deviation $(\mathrm{M} \pm \mathrm{SD})$. Positive control: $75.0 \mu \mathrm{M}$ curcumin and Solvent control: $0.5 \%$ DMSO. One-way ANOVA with Tukey post-hoc tests (treated cells versus solvent control). ${ }^{*} p<0.05 * * p<0.01$ $* * * p<0.001$. 

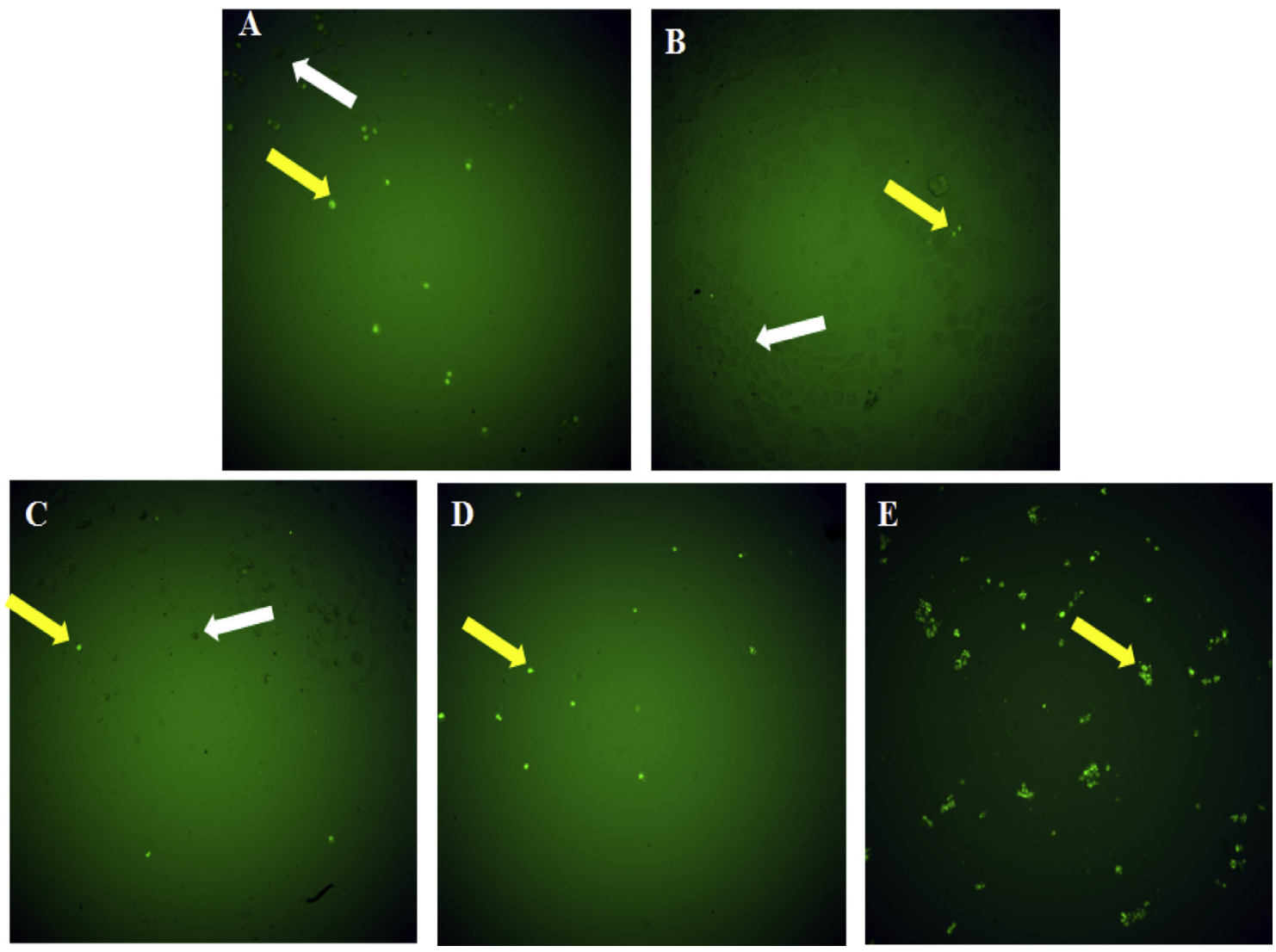

Fig. 4. Images from the TUNEL assay. Yellow arrow: TUNEL-positive cells, white arrows: TUNEL-negative cells. A) Positive control (75.00 $\mu \mathrm{M}$ curcumin); B) Solvent control (0.5\% DMSO); C, D, E) Treatments with NTB for $24 \mathrm{~h}$ at concentrations of 30.0, 60.0, and $120.0 \mu \mathrm{M}$, respectively. (For interpretation of the references to colour in this figure legend, the reader is referred to the web version of this article.)

with $15.0 \mu \mathrm{M}$ of NTB reduced ENO1 expression $(p<0.05)$ and the concentrations of $7.50 \mu \mathrm{M}$ not show any significance when compared to the cells without the treatment, but there was no change in ALDOA expression. At a higher concentration $(30.0 \mu \mathrm{M})$, NTB reduced both ALDOA and ENO1 levels significantly $(p<0.001$ and $p<0.01$, respectively) (Fig. 6).

\section{Discussion}

Guanidine alkaloids derived from P.nitens have a broad spectrum of biological activities (Regasini et al., 2008,2010). In the present study, NTB showed moderate to high capacity to decrease cell viability and induce cytotoxicity related to apoptosis in cells immortalized by HPV16. These observations confirm previous results demonstrating the cytotoxic effects of alkaloids isolated from plants extracts against human cervical cancer (Kma, 2013; Xu and Zhang, 2015).

In order to investigate whether cell death was caused by apoptosis, we performed a TUNEL assay. Apoptotic bodies were observed through microscopy in SiHa cells after treatment. The increase of TUNEL-positive cells, confirming the occurrence of DNA fragmentation, also indicated that NTB was able to induce apoptosis.

Apoptosis, a mechanism of programmed cell death, is crucial in the development and homeostasis of normal tissues (Hassan et al., 2014). Several conventional drugs used in anticancer therapy are believed to kill cancer cells by inducing apoptosis (Kundu et al., 2005). All events taking place during this process are the result of controlling key mechanisms to minimize cell damage in neighboring regions. These events are coordinated mostly, but not exclusively, by a family of proteases known as caspases (Taylor et al., 2008). The higher levels of active caspase 3 and 7 found in our study indicated the capability of NTB to induce apoptosis via caspase effectors.
Reprogrammed energy metabolism is regarded as an emerging hallmark of cancer. The Warburg effect is a commonly occurring phenomenon in tumors where cancer cells preferentially utilize glucose through glycolysis over oxidative phosphorylation, even under aerobic conditions. Without oxidative phosphorylation, apoptosis may not occur and cells can multiply without adequate control mechanisms (Dai et al., 2015; Hernández et al., 2014). Berendzen et al. (2006) found a relationship between metabolic activity and the reestablishment of the apoptotic pathway in these cells. An intervention targeting the apoptotic pathway of neoplastic cells could reverse this process, thereby regulating the cell population.

To further explore the molecular mechanisms underlying the apoptotic effect of NTB, we performed proteomic analysis. Four differentially expressed proteins associated with glucose metabolism were found to be down-regulated in NTB-treated SiHa cells. Expression levels of two of these (ALDOA and ENO1) were verified by western blotting.

ALDOA was found to be 20 -fold less expressed in SiHa cells treated with NTB compared to that in untreated cells. This protein is a key enzyme in the glycolytic pathway, responsible for the reversible conversion of fructose-1,6-bisphosphate to glyceraldehyde 3-phosphate and dihydroxyacetone phosphate, and also contributes to other cellular functions such as regulation of cell morphology and mobility (Du et at., 2014). ALDOA overexpression has been associated with several types of cancer, tumor metastasis, poor prognosis, and recently has been described as an oncogene in highly metastatic pancreatic cancer ( $\mathrm{Ji}$ et al., 2016)

The multifunctional protein G3PD also had decreased expression in SiHa cells exposed to NTB. G3PD plays a role in energy production in glycolysis via the conversion of glyceraldehyde 3-phosphate into the 1,3-bisphosphoglycerate molecule (Dai et al., 2015). Evidence indicates that G3PD responds to stressful stimuli by translocating to the nucleus, 
$5 \mathbf{A}$
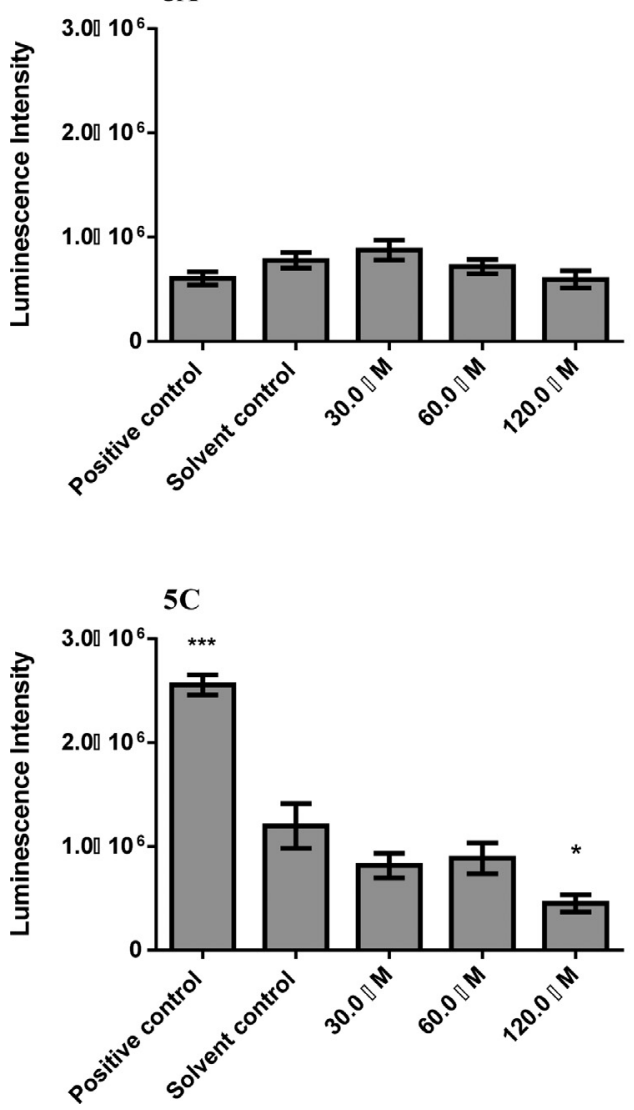

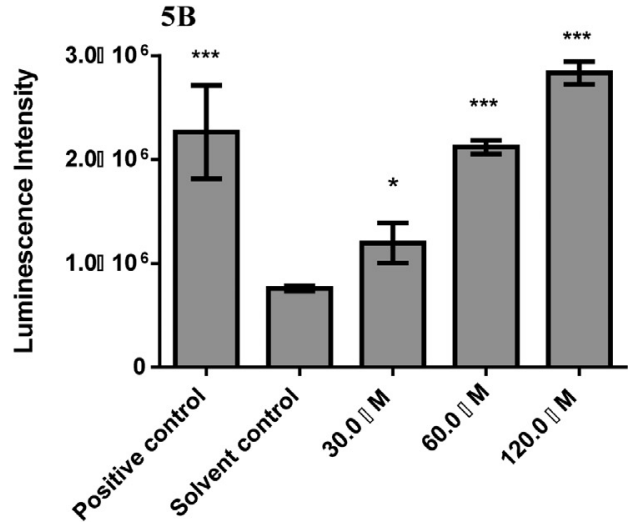

Fig. 5. A, B and C. Chemiluminescence apoptosis assay: activation of caspases $3 / 7$. SiHa cells treated with NTB for 6,12 , and $24 \mathrm{~h}$ respectively. The data refer to the means of three independent experiments and standard error $(\mathrm{M} \pm \mathrm{EP})$. Positive control: $75.0 \mu \mathrm{M}$ curcumin and Solvent control: $0.5 \%$ DMSO). One-way ANOVA with Tukey posthoc tests (treated cells versus solvent control). ${ }^{*} p<0.05 * * p<0.01 * * * p<0.001$. where it is a key component in mediating cell division and DNA repair. The decrease in production of G3PD caused by NTB in SiHa cells, besides affecting the generation of ATP via glycolysis, may also interfere in an opposing manner when this protein is translocated to the nucleus (Nicholls et al., 2012).

We observed a sub-expression of PKM, an enzyme that regulates the final rate-limiting step of glycolysis and catalyzes the transfer of a phosphate group from phosphoenolpyruvate to adenosine diphosphate (Kim et al., 2015). Recent findings have shown that abnormal metabolism of glucose mediated by PKM overexpression favors the growth and spread of cancer, particularly in oral squamous cell carcinomas and A549 alveolar adenocarcinoma cells, suggesting increased proliferation with decreased apoptosis (Wang et al., 2015). PKM sub-expression in SiHa cells induced by NTB treatment provides further evidence of the action of NTB in the glycolytic pathway, with a possible decrease in the Warburg effect.

The results of our study demonstrated that the multifunctional protein ENO1 was also sub-expressed in SiHa cells. This protein functions in the glycolytic pathway, but also plays a role in the expansion and formation of tumors (Gao et al., 2013). Fu et al. (2015) demonstrated that the overexpression of ENO1 in lung carcinoma cells increased glycolysis, proliferation, clone formation, and invasion in vitro, as well as tumorigenesis and metastasis in vivo. The observation of sub- expression induced by NTB further supports the notion that natural alkaloids can interfere in the glycolytic pathway, specifically the formation of phosphoenolpyruvate molecules in the final steps of the process.

Most types of cancer cells, including cervical, depend disproportionately on the energy generated from the glycolytic pathway, even in the presence of oxygen (Glushakova et al., 2009). The results showing ALDOA, G3PD, PKM, and ENO1 sub-expression suggest that treatment with NTB in SiHa cells may have a direct effect on decrease in production and generation of ATP. This may be attributable to the fact that agents that suppress cellular respiration or disrupt oxidative phosphorylation have been shown to trigger cell death (Gogvadze et al., 2008). Our study showed that NTB can induced a decrease in the Warburg effect, through reduction in the expression of proteins essential in the glycolic pathway (ALDOA, G3PD, PKM, and ENO1) as well as promotion of apoptosis, however more experimental evidence are needed and further studies should continue to explore the effect of NTB on cervical carcinoma cells.

\section{Conclusions}

The guanidine alkaloid NTB, extracted from $P$. nitens, showed concentration-dependent cytotoxicity in cervical carcinoma lines

Table 1

Differentially expressed proteins in the SiHa cell line. Values are expressed by means of the fold change \pm standard deviation. Fold change ratio $\leq 0.7$ represents underexpressed proteins; Fold change $\geq 1,3$ represents overexpressed proteins. Peptide sequence coverage and Mascot ion score.

\begin{tabular}{|c|c|c|c|c|}
\hline Differentially expressed proteins & Gene name & Fold change \pm SD & Peptide sequence & Mascot ion score \\
\hline ALDOA: Aldolase A fructose-bisphosphate & $A L D O A$ & $0.05 \pm 0.01$ & VNPCIGGVILFHETLYQK & 27.8 \\
\hline PKM: Pyruvate Kinase & PKM & $0.60 \pm 0.02$ & AGKPVICATQMLESMIK & 63.5 \\
\hline ENO1: Alpha-enolase & ENO1 & $0.65 \pm 0.01$ & AGYTDKVVIGMDVAASEFFR & 54.0 \\
\hline G3P: Glyceraldehyde-3-phosphate dehydrogenase & GAPDH & $0.72 \pm 0.10$ & GALQNIIPASTGAAK & 53.6 \\
\hline
\end{tabular}


ALDOA

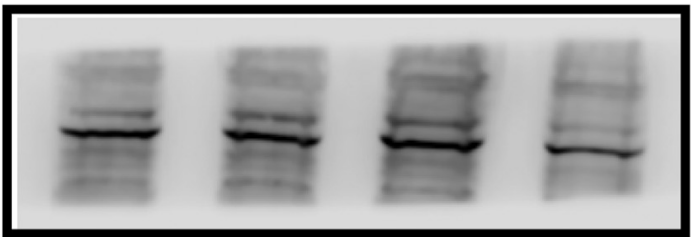

ENO1

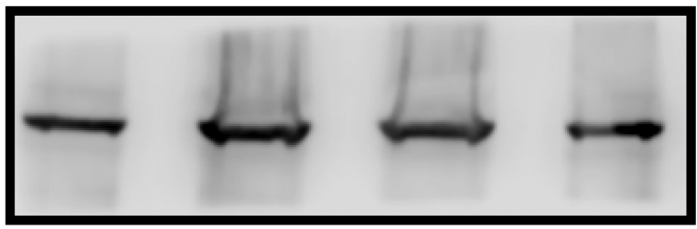

B-Actin

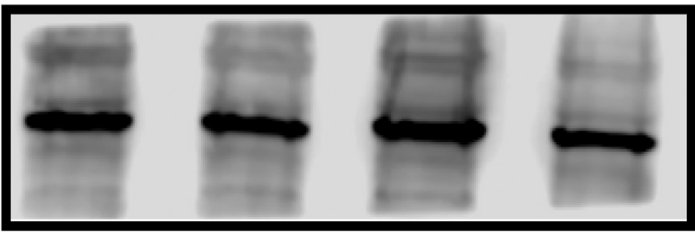

6A

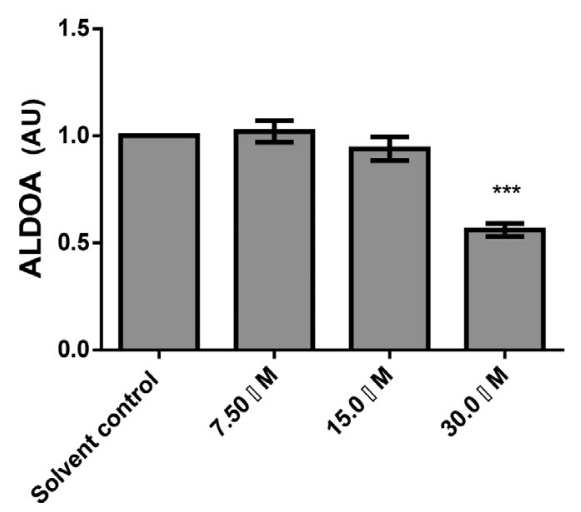

6B

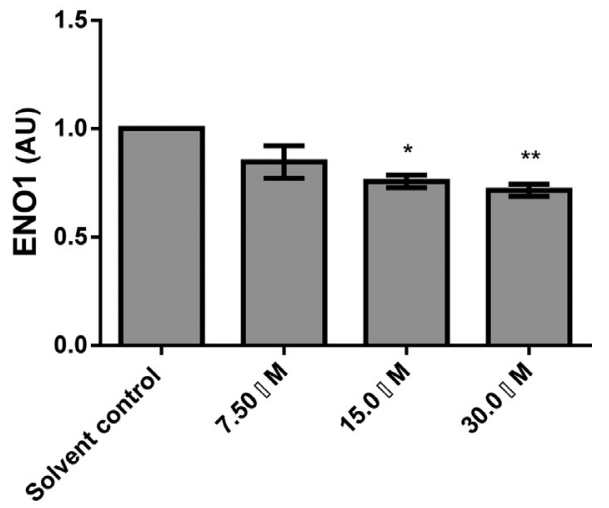

Fig. 6. Western blotting - ALDOA and ENO1 proteins from SiHa cells, $\beta$-Actin was used for loading control. Solvent control: $0.5 \%$ DMSO and NTB at concentrations of 7.5, 15.0, and 30.0 $\mu \mathrm{M}$. Fig. 6A - Data refer to densitometry of ALDOA protein (Arbitrary units, AU) from SiHa cells. Fig. 6B - Densitometry of ENO1 protein (Arbitrary units, AU) from SiHa cells. Solvent control: $0.5 \%$ DMSO and NTB at concentrations of 7.5, 15.0, and $30.0 \mu$ M. Data refer to the means of three independent experiments and standard error $\left(\mathrm{M} \pm \mathrm{SD}\right.$ ). One-way ANOVA with Tukey post-hoc tests (treated cells versus solvent control). ${ }^{*} p<0.05 * * p<0.01 * * * p<0.001$.

immortalized by HPV16. Cell death in the SiHa cells exposed to NTB, analyzed by the TUNEL method, showed a result of apoptosis with activation of caspases $3 / 7$. Results of the differential proteomic analysis suggest that NTB decreased expression of several enzymes involved in glycolysis and further, this mechanism of action might be leveraged as a therapeutic target for cervical cancer.

\section{Conflict of interest}

The authors declare that they have no competing interests.

\section{Acknowledgments}

We are sincerely thankful to the Laboratory of Clinical Cytology and Cell Biology of the Faculty of Pharmaceutical Sciences of Araraquara of the State University of São Paulo and Laboratory of Protein Chemistry of the Medical Faculty of the Ribeirão Preto of the University of São Paulo for providing help and technical support for current project.

\section{Funding}

The authors gratefully acknowledge financial support from the National Council for Scientific and Technological Development (CNPq, Conselho Nacional de Desenvolvimento Científico e Tecnológico), National Institute of Science and Technology - INCT BioNat, grant \# 465637/2014-0, and the State of Sao Paulo Research Foundation (FAPESP, Fundação de Amparo à Pesquisa do Estado de São Paulo), grant \# 2014/50926-0, Brazil.

\section{Supplementary materials}

Supplementary material associated with this article can be found, in the online version, at doi:10.1016/j.phymed.2018.05.016.

\section{References}

Berendzen, K., Douglas, W.T., Shuster, J., Stacpoole, P.W., 2006. Therapeutic potential of dichloroacetate for pyruvate dehydrogenase complex deficiency. Mitochondrion 6, $126-135$. 
Chavan, P., Joshi, K., Patwardhan, B., 2006. DNA microarrays in herbal drug research. Evidence-Based Complementary Altern. Med. 3, 447-457.

Dai, W., Wang, F., Lu, J., Xia, Y., He, L., Chen, K., Li, J., Li, S., Liu, T., Zheng, Y., Wang, J., Lu, W., Zhou, Y., Yin, Q., Abudumijiti, H., Chen, R., Zhang, R., Zhou, L., Zhou, Z., Zhu, R., Yang, J., Wang, C., Zhang, H., Zhou, Y., Xu, L., Guo, C., 2015. By reducing hexokinase 2, resveratrol induces apoptosis in HCC cells addicted to aerobic glycolysis and inhibits tumor growth in mice. Oncotarget 6, 13703-13717.

Duarte, R.A., Mello, E.R., Araki, C., Bolzani, V.S., Siqueira e Silva, D.H., Regasini, L.O., Silva, T.G.A., De Morais, M.C.C., Ximenes, V.F., Soares, C.P., 2010. Alkaloids extracted from Pterogyne nitens induce apoptosis in malignant breast cell line. Tumour Biol. J. Int. Soc. Oncodevelopmental Biol. Med. 31, 513-522.

Du, S., Guan, Z., Hao, L., Song, Y., Wang, L., Gong, L., Liu, L., Qi, X., Hou, Z., Shao, S. 2014. Fructose-bisphosphate aldolase A is a potential metastasis-associated marker of lung squamous cell carcinoma and promotes lung cell tumorigenesis and migration. PLoS One 9, e85804.

Ferlay, J., Soerjomataram, I., Dikshit, R., Eser, S., Mathers, C., Rebelo, M., Parkin, D., Forman, D., Bray, F., 2014. Cancer incidence and mortality worldwide: sources, methods and major patterns in GLOBOCAN 2012. Epidemiology 135, 359-386.

Fu, Q.F., Liu, Y., Fan, Y., Hua, S.N., Qu, H.Y., Dong, S.W., Li, R.L., Zhao, M.Y., Zhen, Y., Yu, X.L., Chen, Y.Y., Luo, R.C., Li, R., Li, L.B., Deng, X.J., Fang, W.Y., Liu, Z., Song, X., 2015. Alpha-enolase promotes cell glycolysis, growth, migration, and invasion in non-small cell lung cancer through FAK-mediated PI3K/AKT pathway. J. Hematol. Oncol. 8, 22-29.

Gao, J., Zhao, R., Xue, Y., Niu, Z., Cui, K., Yu, F., Zhang, B., Li, S., 2013. Role of enolase-1 in response to hypoxia in breast cancer: exploring the mechanisms of action. Oncol. Rep. 29, 1322-1332.

Gebremariam, T., 2016. Human papillomavirus related cervical cancer and anticipated vaccination challenges in Ethiopia. Int. J. Health Sci. 10, 137-143.

Gogvadze, V., Orrenius, S., Zhivotovsky, B., 2008. Mitochondria in cancer cells: what is so special about them. Trends Cell Biol. 18, 165-173.

Glushakova, L.G., Lisankie, M.J., Eruslanov, E.B., Ojano-Dirain, C., Zolotukhin, I., Liu, C., Srivastava, A., Stacpoole, P.W., 2009. AAV3-mediated transfer and expression of the pyruvate dehydrogenase E1 alpha subunit gene causes metabolic remodeling and apoptosis of human liver cancer cells. Mol. Genet. Metab. 98, 289-299.

Hassan, M., El-khattouti, A., Haikel, Y., Megahed, M., 2014. Signaling pathways as therapeutic target in tumor treatment. VRI Cell Signaling 2, 1-21.

Hernández, J.F., Urueña, C.P., Cifuentes, M.C., Sandoval, T.A., Pombo, L.M., Castañeda, D., Asea, A., Fiorentino, S., 2014. A Petiveria alliacea standardized fraction induces breast adenocarcinoma cell death by modulating glycolytic metabolism. J. Ethnopharmacol. 153, 641-649.

Ji, S., Zhang, B., Liu, J., Yi, Q., Liang, C., Shi, S., Jin, K., Liang, D., Xu, W., Xu, H., Wang, W., Wu, C., Liu, L., Liu, C., Xu, J., Ni, Q., Yu, X., 2016. ALDOA functions as an oncogene in the highly metastatic pancreatic cancer. Cancer Lett. 374, 127-135.

Kim, D.J., Park, Y.S., Kang, M.G., You, Y.M., Jung, Y., Koo, H., 2015. Pyruvate kinase isoenzyme M2 is a therapeutic target of gemcitabine-resistant pancreatic cancer cells. Exp. Cell Res. 336, 119-129.

Kundu, T., Dey, S., Roy, M., Siddiqi, M., Bhattacharya, R.K., 2005. Induction of apoptosis in human leukemia cells by black tea and its polyphenol thea flavin. Cancer Lett. 230, 111-121.

Kma, L., 2013. Roles of plant extracts and constituents in cervical cancer therapy. Asian Pac. J. Cancer Prev. 14, 3429-3436.

Lai, S.L., Wong, P.F., Lim, T.K., Lin, Q., Mustafa, M.R., 2014. iTRAQ-based proteomic identification of proteins involved in anti-angiogenic effects of Panduratin A on HUVECs. Phytomedicine 22, 203-212.

Lai, S.L., Wong, P.F., Lim, T.K., Lin, Q., Mustafa, M.R., 2015. Cytotoxic mechanisms of Panduratin A on A375 melanoma cells: a quantitative and temporal proteomics analysis. Proteomics 15, 1608-1621.

Lee, S.J., Hwang, S.O., Noh, E.J., Kim, D.U., Nam, M., Kim, J.H., Nam, J.H., Hoe, K.L., 2014. Transactivation of bad by vorinostat-induced acetylated p53 enhances doxorubicin-induced cytotoxicity in cervical cancer cells. Exp. Mol. Med. 46, e76.

Nicholls, C., Pinto, A.R., Li, H., Li, L., Wang, L., Simpson, R., Liu, J.P., 2012. Glyceraldehyde-3-phosphate dehydrogenase (GAPDH) induces cancer cell senescence by interacting with telomerase RNA component. Proc. Natl. Acad. Sci. 109, 13308-13313.

Regasini, L.O., Vellosa, J.C.R., Silva, D.H.S., Furlan, M., Oliveira, O.M.M., Khalil, N.M., Brunetti, I.L., Young, M.C.M., Barreiro, E.J., Bolzani, V.S., 2008. Flavonols from Pterogyne nitens and their evaluation as myeloperoxidase inhibitors. Phytochemistry 69, 1739-1744.

Regasini, L.O., Castro-Gamboa, I., Silva, D.H.S.S., Furlan, M., Barreiro, E.J., Ferreira, P.M.P., Pessoa, C., Lotufo, L.V.C., Moraes, M.O., Young, M.C.M., Bolzani, V.S., 2009. Cytotoxic guanidine alkaloids from Pterogyne nitens. J. Nat. Prod. 72, 473-476.

Regasini, L.O., Pivatto, M., Scorzoni, L., Benaducci, T., Fusco-Almeida, A.M., Giannini, M.J.S.M., Barreiro, E.J., Silva, D.H.S.S., Bolzani, V.S., 2010. Antimicrobial activity of Pterogyne nitens Tul., Fabaceae, against opportunistic fungi. Revista brasileira de farmacognosia 20, 706-711.

Rosa, M.I., Medeiros, L.R., Rosa, D.D., Bozzeti, M.C., Silva, F.R., 2009. Papilomavírus humano e neoplasia cervical. Caderno de Saúde Pública 25, 953-964.

Shanmugam, M.K., Lee, J.H., Chai, E.Z., Kanchi, M.M., Kar, S., Arfuso, F., Dharmarajan, A., Kumar, A.P., Ramar, P.S., Looi, C.Y., Mustafa, M.R., Tergaonkar, V., Bishayee, A., Ahn, K.S., Sethi, G., 2016. Cancer prevention and therapy through the modulation of transcription factors by bioactive natural compounds. Sem. Cancer Biol. 1-13.

Skehan, P., Storeng, R., 1990. New colorimetric cytotoxicity assay for anticancer-drug screening. J. Natl. Cancer Inst. 82, 1107-1112.

Tajima, Y., Nakagawa, H., Tamura, A., Kadioglu, O., Satake, K., Mitani, Y., Murase, H., Regasini, L.O., Bolzani, V.S., Ishikawa, T., Fricker, G., Efferth, T., Nitensidine, A., 2014. A guanidine alkaloid from Pterogyne nitens, is a novel substrate for human ABC transporter ABCB1. Phytomedicine 21, 323-332.

Taylor, R.C., Cullen, S.P., Martin, S.J., 2008. Apoptosis: controlled demolition at the cellular level. Nat. Rev. Mol. Cell Biol. 9, 231-241.

Ulrich-Merzenich, G., Zeitler, H., Jobst, D., 2007. Application of the "-Omic-" technologies in phytomedicine. Phytomedicine 14, 70-82.

Verpoorte, R., Choi, Y.H., Kim, H.K., 2005. Ethnopharmacology and systems biology: a perfect holistic match. J. Ethnopharmacol. 100, 53-56.

Voigt, W., 2005. Sulforhodamine B assay and chemosensitivity. Methods Mol. Med. 110, 39-48.

Wang, Y., Zhang, X., Zhang, Y., Zhu, Y., Yuan, C., OI, B., Zhang, W., Wang, D., 2015. Overexpression of pyruvate kinase M2 associates with aggressive clinicopathological features and unfavorable prognosis in oral squamous cell carcinoma. Cancer Biol. Ther. 16, 839-845.

Xu, Q.X., Zhang, Z.Y., 2015. High-risk human papillomavirus genotypes in cervical lesions and vaccination challenges in China. Asian Pac. J. Cancer Prev. 16, 2193-2197.

Zaman, M.S., Chauhan, N., Yallapu, M.M., Gara, R.K., Maher, D.M., Kumari, S., Sikander, M., Khan, S., Zafar, N., Jaggi, M., Chauhan, S.C., 2016. Curcumin nanoformulation for cervical cancer treatment. Sci. Rep. 6, 20051. 